\title{
PATIENT ACCEPTABILITY OF HILOTHERAPY IMMEDIATELY POST SEPTORHINOPLASTY
}

\section{WHS}

\section{Barts Health}

NHS Trust

\section{A Carter, S Jayaraj. Whipps Cross University Hospital, London, UK}

\section{Aims}

Septorhinoplasty patients often experience significant facial swelling, ecchymosis, and epistaxis following their operation, which can traditionally be improved with the use of cooling methods such as ice $^{1}$. Hilotherapy is a water circulating cooling device that delivers a continuous temperature via a mask or cuff to a specific area. It is currently used in maxillofacial, orthodontic, and orthopaedic procedures and has been shown to decrease pain and swelling post operatively2. We tested the 'nose cuff' in the direct post operative phase of septorhinoplasty to see if the equipment was well tolerated and acceptable to patients prior to considering wider use and investigation into the potential benefits in our patient cohort.

\section{Method}

Patients undergoing septorhinoplasty were if they would be amenable to using the hilotherm 'nose cuff ' postoperatively in recovery and were asked afterwards about their experience and acceptability of the device.



\section{Results}

$100 \%$ of patients felt that the Hilotherm nose cuff was acceptable in the post operative period and both patients said that if they had been offered the equipment to take home that they would have used it upon discharge. One patient initially found the 'nose cuff' uncomfortable upon waking in recovery, but after swift readjustment felt that it was comfortable.

\section{Conclusion}

Hilotherapy has been shown in other facial operations to decrease pain and swelling and thereby hypothesised to promote healing. Our study indicates the 'nose cuff' is well tolerated immediately post septorhinoplasty in this small pilot sample and supports further use and studies into the potential benefits after septorhinoplasty surgery.

\section{References}

1. Hettige R, Mansell N. Limiting oedema, ecchymosis and haemorrhage in septorhinoplasty with cooled swabs. Ann R Coll Surg Engl. 2014 96(5):395-396

2. Bell E, Rendine G, Mazzone N. Cold therpay in maxillofacial surgery. J Craniofac Surg. 2009 20(3):878-80 